\title{
A Gamified Model for the Building Site: A Solution to Motivate Construction Wokers in Pandemic Time
}

\author{
Regina Leite ${ }^{1,2^{*}}$, Lynn Alves ${ }^{3,1}$ \\ ${ }^{1}$ SENAI-CIMATEC University Center - Doctoral Program in Management and Industrial Technology; ${ }^{2}$ Federal Institute \\ of Bahia, Department of Civil Construction; ${ }^{3}$ Federal University of Bahia, Institute of Sciences and Humanities; Salvador,
} Bahia, Brazil

\begin{abstract}
This article aims to present the first results of a study that investigates how construction companies can use gamification to help workers assume appropriate behaviors and motivate construction teams to achieve their production goals. It is an exploratory, empirical, qualitative research, for which the methodological approach is Design Science Research. A closed questionnaire was carried out to construction workers to understand the context of the workplace. This tool aims to investigate motivational aspects, and another questionnaire, with engineers, aims to identify which production problems to address in a proposal for a gamified model. The results show that most workers have a need to be recognized and that the proposed solution can contribute to the continuous improvement of the work environment. The article presents possibilities of using gamification in the construction environment to help workers in the prevention against COVID-19.

Keywords: Gamification; Motivation; COVID-19; Production Control; Construction.
\end{abstract}

\section{Introduction}

In 2020 the world is experiencing a pandemic never imagined. Everyone was preparing for a nuclear war, but it was never thought that a small virus could alter the routine of everyone on the planet. Researchers from all over the world started to look for a vaccine [1,2], which has already been discovered and is in production. The question is: "After the COVID-19 pandemic, will there be others? What will everyday life be like after COVID-19?" Certainly, there will be changes and learning in all sectors that are going to be permanent. More specifically in the Civil Construction sector, many are wondering: "What does the new normal look like?" In the context of Civil Construction, since the emergence of Lean Construction [3], the construction industry has been pursuing the efficient implementation of lean production in

Received on 10 September 2020; revised 21 September 2020. Address for correspondence: Regina Maria Cunha Leite, Federal Institute of Bahia, Department of Civil Construction, Rua Emídio dos Santos, s/n - Barbalho, Campus Salvador, 40301-015. Salvador - BA, Brazil. Phone/Fax: (5571) 21029535. E-mail: reginamaria.leite@hotmail.com.

J Bioeng. Tech. Appl. Health 2020;3(4):319-327.

(C) 2020 by SENAI CIMATEC. All rights reserved. construction sites. Lean practices are deeply connected to human behavior, and there is no way to separate their effects. Furthermore, at the construction site, projects are complex and involve several intervening factors that work simultaneously, often resulting in unnecessary rework, movement of people, and material handling.

Thus, despite the discussions about lean construction [3-5], the reality of the construction site is still characterized by an environment where communication between managers and workers is deficient, the workforce is rotating and little engaged, the workers perform manual and repetitive work [6] and have a low qualification and education. Furthermore, the diversity of services and the dynamic way in which they take place can make production control a complex activity, and it becomes arduous to meet the goals set in the planning [7].

So, one of the significant challenges during construction is to control its processes so that they occur as planned and, if something goes different from the program, to identify the deviations quickly and make improvements. These actions and their results on a construction site directly involve the performance of workers. Consequently, the importance of investing in improvements in working conditions is evident, 
since the satisfaction and well-being of workers will reflect in more dedication and commitment to the performance of their duties.

Construction companies generally have few visual mechanisms to inspire, motivate, or instruct workers to do their jobs more effectively, efficiently, and safely [5]. There is a need for structures to facilitate the feedback process to the worker and to make relevant information transparent to them [5]. Little feedback on the work in progress and the performance of the workers involved in the process leads to low engagement at the construction site and makes it difficult to meet production goals effectively [8].

It is in this context that gamification, defined as the insertion of game elements in non-game contexts [9], appears as an innovative idea to improve communication between managers and workers, promoting motivation and engagement. The strategy aims to motivate the worker to perform repetitive tasks, encouraging them to assume the player's behavior. So, how can gamification strategies improveproduction control and workers' motivation at the construction site? The purpose of this article is to present the first results of a research that investigates, through Design Science Research, how construction companies can use technology to involve and help workers to assume appropriate behaviors and motivate construction teams to achieve their goals, incorporating game elements into applications and processes through gamification.

\section{Gamification}

There are many definitions for the term gamification [9-11]. Deterding refers to gamification as adding game mechanisms to everyday life contexts to provide fun experiences and improve the motivation of those involved. It is important to note that, despite the use of game elements, gamified applications are not exactly games. Gamification is usually used to influence human motivation and behavior positively $[11,12]$. Therefore, several game strategies can be used in gamification, such as Avatars, Teammates, Points, Badges, Leaderboards, Narrative, Performance Charts, Rewards, Voting, Bets, Levels, Missions, Progress Bar, Collaboration, Unlocking content, Rules, Online Store, Missions, Deadline and Feedback [12-16].

Chou [15] states that most systems are designed to facilitate tasks to be performed in the shortest possible time. Therefore, during the design phase, it is necessary to consider that the people who perform these activities have emotions, insecurities, and opinions about what is expected of them, or about how they should achieve their professional goals.

Deterding [17] presents two rhetorics for the conception of a gamification process:

1. Rhetoric of chosen architecture that presents human beings with rational and strategic agents and gamification as an information system with incentives. This rhetoric launches gamification as a refinement of existing business practices.

2. Humanist rhetoric is based on positive design psychology and virtue ethics. This rhetoric believes that human beings are social, emotional creators of meaning and oriented towards growth. It is directly focused on the well-being of the worker.

\section{Gamification in the Production}

In 2012, Korn \& Schmidt [16] introduced the first concept of gamification in industrial workplaces. In the motion EAP research project (2013-2016), ways of improving assistance systems in production environments are explored. In parallel, in the same year, Leite [6] began his studies of gamification at the construction site. The research by Korn \& Schmidt [18] proposes the implementation of gamification elements as an avatar and uses color-coding to visualize the progression of time, especially for the automobile industry. Similarly, Leite's research [6] uses elements such as points, ranking, and leaderboards to motivate workers to comply with weekly planning goals. 
Warmelink and colleagues [19], present a Systematic Literature Review (SLR) on gamification in industrial production from 2012 to 2017. SLR was carried out in May 2017. This review results in sixteen studies, twelve of which were developed by Korn \& Schmidt [18] and two by Leite [6] and Morêda Neto [8]. This highlights the research gap in the production area.

\section{The Protocol in the Construction Sector}

For safe workplace activities during the COVID-19 pandemic, a sectoral protocol was launched to establish recommendations for the application of preventive measures due to COVID-19 in civil construction works [2]. In these environments, there is a concern with the minimum distance between employees, hand hygiene, Personal Protection Equipment, and the tools used by them. Thus, it is essential to raise awareness among this audience through lectures, the establishment of shifts to avoid cluster, and the constant hygiene of the environments, the seats, and other surfaces used by workers.

Usually, some workers have difficulty using the Personal Protection Equipment required by regulatory safety standards. There is also difficulty in communication between the tactical and operational levels at the construction site [6]. Therefore, to overcome these difficulties, gamifying some behavioral rules can serve as an incentive for the worker not to neglect their health in the face of the need to work in a pandemic time. Some examples of the protocols established for the sector: maintaining a safe distance of $1.5 \mathrm{~m}$ between workers, using a mask, glasses, and face shield; adopting continuous hand hygiene procedures; leaving tools sanitized for the next day; avoid crowding in the intervals; all waste and disposable Personal Protection Equipment's must be disposed of safely, in places indicated on the construction site; participating in lectures on the risk of coronavirus (COVID -19), and measures to prevent contagion, as well as company protocols (Figure 1) [2].

\section{Materials and Methods}

Design Science Research was selected as the most appropriate methodological approach for the development of this work because it is used in research wherein the objective is to create, develop, and explore new solutions [20]. In this case, it is an exploratory, empirical, qualitative research to evaluate strategies to improve production control and engagement of construction workers through the creation and implantation of a gamified artifact. The research consists of 4 phases: (1) the understanding phase, (2) the Development phase, (3) the analysis phase, and (4) the Phase of evaluations and reflections (Figure 2).

In the phase of understanding the problem, starting from the bibliographic review carried out in the first stage, the knowledge gap that gave rise to the real problem was identified; for this, an exploratory study was carried out. Contact was made with two companies that practice Lean construction in their construction sites. The two sites were visited to determine the requirements, the plan, and to understand the process for gamification.

Focusing on the problem defined in the previous step, we used data from the research on motivation developed by the research group GCIS-IFBA for the application of questionnaires with the research subjects (supervisors and workers) seeking to better understand the following points:

1. What does the worker, the gamification user, expect from the process?

2. What would motivate them to participate in gamification?

3. What does the company, the environment to be gamified, need?

4. What are the desired behaviors to be motivated by gamification? These questions guided the survey of requirements for the gamified solution.

From this knowledge, it was possible to perform the selection of software and hardware to develop the artifact and prepare the first proposal of the model. 
Figure 1. Application of preventive measures.

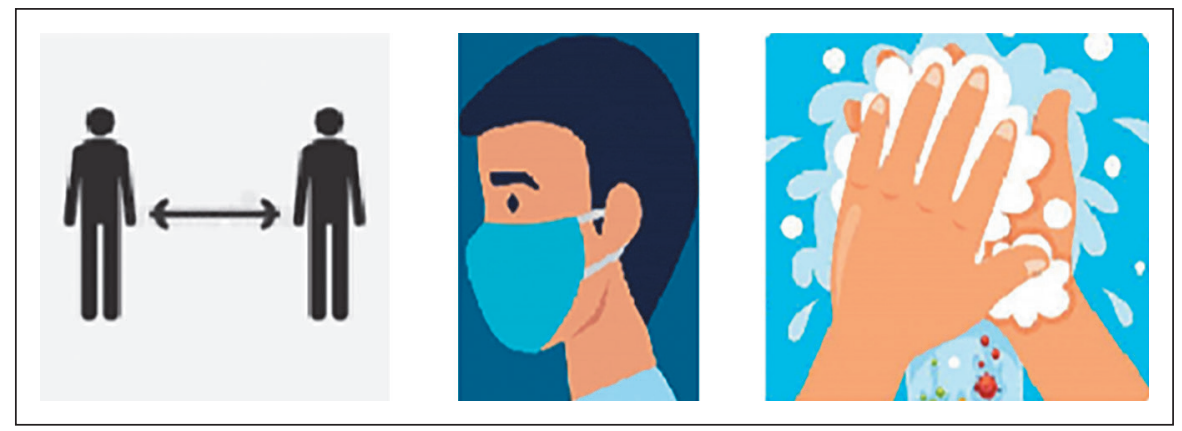

Source: Public domain images.

Figure 2. Research outline.

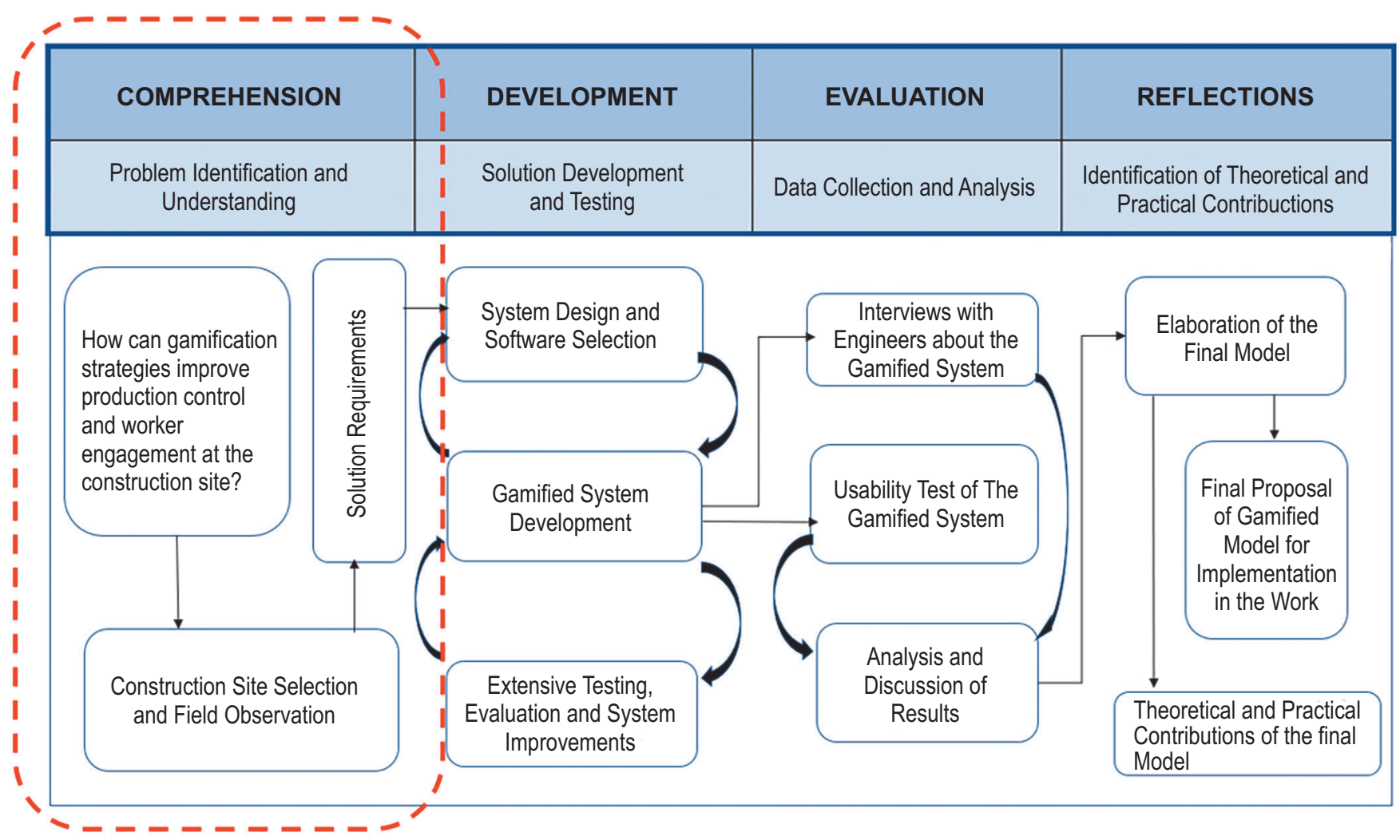

\section{Results and Discussion}

Understanding the current situation is the first step towards solving the problem. For this, we carried out an exploratory study to obtain a requirements survey and select the software and hardware to create a model for solving the problem.
The Preliminary Exploratory Study

The exploratory study had two objectives:

1. Identify the needs of workers and engineers to insert gamification strategies on the construction site;

2. Knowing the characteristics of the workers. 
For this, we conducted questionnaires with the target audience that had the following samples: 109 workers answered, 108 of which were male and 1 female. Average age group: 35.76 years. Education: $46.8 \%$ did not complete elementary school, $27.5 \%$ of them finished elementary school, and $25.7 \%$ completed middle school. Composition: 59 professionals, 37 helpers, and 13 servants. The empirical space was the construction site. Regarding the Engineers, we received twenty-six responses, and their experiences ranged from 5 to 35 years. The first question in the questionnaire was: what does work mean to you? And it is aimed at identifying how the construction worker positions himself concerning the work he does.

In Figure 3, 96\% of respondents like what they do, and only $3.7 \%$ of them find work an unpleasant activity, exercising it for survival. Then, we tried to probe what motivates the worker. Figure 4 presents the results of this question.

Regarding the motivation to do a better job, the majority (51.4\%) shows an enormous lack of recognition. It is probably related to the lack of feedback. As already noted in past surveys, the worker never or rarely ever receives a response (feedback) on the achievement of the weekly goals. The next questions were asked to understand the worker's relationship with games. Analyzing the results, $71.6 \%$ of workers like to play. At the start, the first ten respondents expressed some discomfort with the question due to their religious line, which perceives games as wrong, and because they did not understand what type of game it was. The researchers were oriented to clarify the issues. After that, the research flowed normally. For those who answered affirmatively to the previous question, a more specific question was asked to find out what they like to play (Figure 5).

Most workers (83.3\%) answered sports games, especially soccer. Some also like cards and board games. These data will support the design of a gamification proposal. We can see from the responses that there is a great sense of collaboration among workers, which leads us to believe that this audience will feel motivated to work with collaboration games, giving greater focus to 'competition between teams and collaboration between peers.' To implement the gamification on the construction site, it is necessary to know the level of involvement of the worker with technological resources. For that, we verified if they have smartphones and what applications they use. $45 \%$ of workers usually play games using their smartphones. This value corresponds to approximately half of the audience, and because playing using a computer or smartphone is not an essential requirement to participate in gamification, this is quite significant to encourage team play. Thus, it is possible to use the device to give gamification feedback to workers, as half of them are already familiar with the game mechanics (ranking, points, and others) it is believed that this will facilitate the learning of the entire group.

Figure 6 illustrates the workers' responses. We see that $84 \%$ of them use WhatsApp, so this tool can be used as a means of communication with the worker during the gamification process at the construction site.

Figure 7 shows the meaning of fun for the worker. For $86.2 \%$ of workers, fun is something pleasurable and part of everyday life. And only $0.9 \%$ of them do not feel entitled to the fun. Therefore, the majority is prepared to accept a playful activity, and a few could reject it.

They understand that fun is something pleasurable and that it is part of everyday life. They liked theidea of gamification and want to participate. As for the engineers (supervisors): they believe that gamifying is interesting to improve the progress of the work and the motivation of the worker. Only $30 \%$ have daily information on worker productivity. Most engineers (96.2\%) believe that the idea of giving feedback to workers is a good one and that it would increase motivation. The use of mechanisms that will motivate workers to carry out their activities to their full potential is well accepted. They liked the idea of gamification and would adopt it at work. 65\% said their companies want to retain employees. 
Figure 3. The job for the worker.

\section{What does work mean to you?}

109 answers

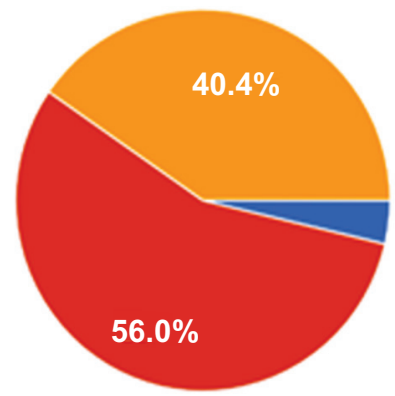

A mandatory and boring activity, just to make money

An activity that you enjoy doing and that also earns money

An incredible activity that fills your life and that also earns money

Figure 4. The motivation for working.

\section{What does motivate you to do a better job?}

109 answers

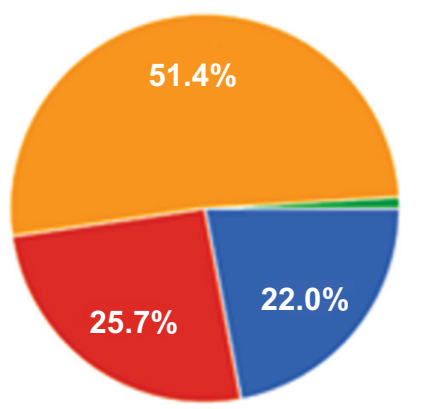

Contributing to the work being ready

Making you feel better, more competent

Showing that you are good at what you do and be recognized

Helping you to grow professionally

Figure 5. What is the games for workers?

\section{If you answered 'Yes', what do you like to play?}

78 answers

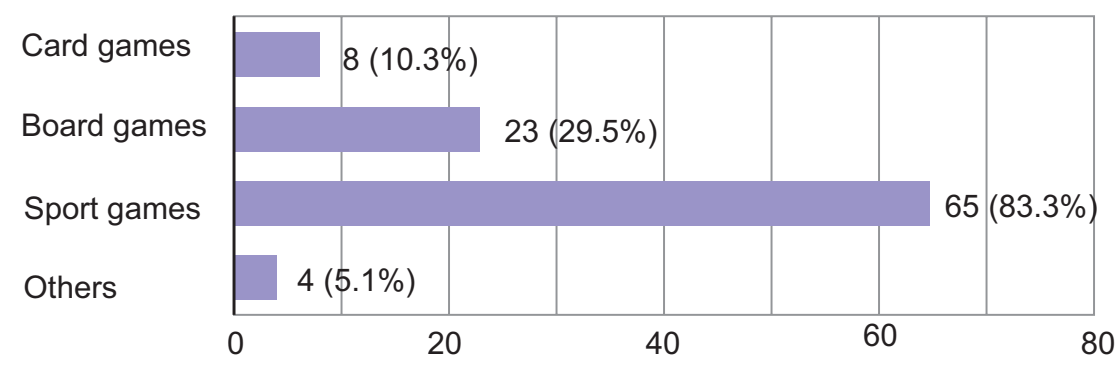

www.jbth.com.br 
Figure 6. App. and social midia used by workers.

Do you have and use Facebook / Instagram / WhatsApp?

109 answers

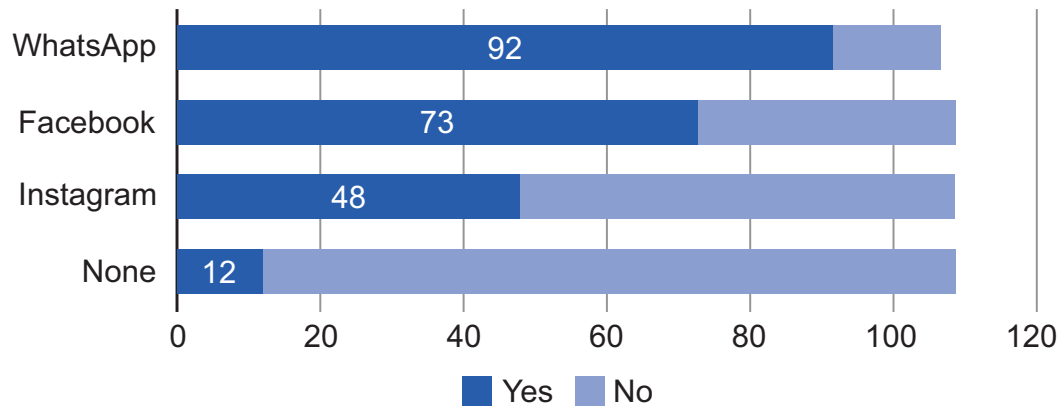

Figure 7. The worker and the fun.

\section{What dos fun mean to you?}

109 answers

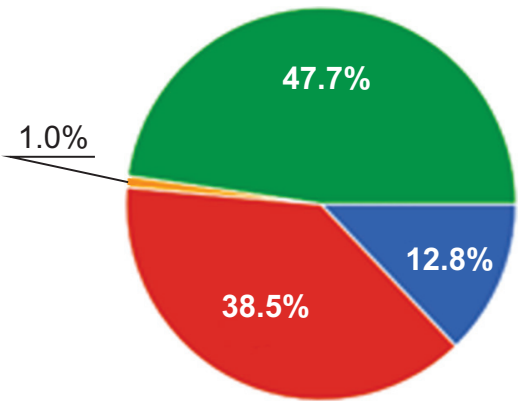

A free activity without responsability, that you can do whatever you want

Something pleasure to do, but without lose focus on reality

Something that only happened when you were child

Something important and necessary for the whole life

\section{Proposal for the Gamified Model}

Amobile device gamified system will be designed to give feedback to the worker on his performance from the data collected from the monitoring of the services. Rules will be developed, together with the project managers, so that the gamified system can assess the worker's performance. Gamification may use points, avatars, and other game mechanisms to encourage participation and improve performance. Only the worker will know his performance.

A gamified interface presented on a monitor strategically installed in the workplace will show the performance of construction teams and the weekly progress of services. This service will be monitored by the site supervisor.

Working in COVID-19 times, individual controls may be necessary, such as the use of masks, frequent 
hand washing, and or use of alcohol, keeping time out regulated by the World Health Organization, and others. This need can be transformed into a gamification rule. The control of these rues can be done by placing a camera in the place available for handwashing. The distance can be measured by an application using the cell phones themselves. The system to be developed must be very flexible in terms of creating rules, so new rules in the event of a pandemic will be easy to implement.

Figure 8 presents a general scheme of the gamified model.

Worker's feedback can be presented through color graphics Green (great), Yellow (reasonable), and Red (bad) already known and used in construction sites, or even by icons such as faces in the same colors (smiles) or other signs that connote performance. Thus, the employee can feel recognized, motivated, and understand the weekly goals, which should improve the team's performance.

\section{Conclusion}

The article aimed to present a proposal for a model for the implementation of gamification to improve production control in civil construction. To support this proposal, a field survey was carried out with 109 workers from which it was possible to establish a profile of the target audience. From this, a gamification model was idealized to make the weekly goals more transparent and to motivate workers to meet them at the construction site. The idealized model proved to be flexible enough to allow for the insertion of new rules, as exemplified by the pandemic situation which requires certain behaviors, which the worker can have difficulty assimilating or finding the motivation to comply with them. This research contributes to the continuous improvement of construction sites to provide a more integrated and safer environment for carrying out the work, establishing more effective

Figure 8. General gamification information scheme at the construction site.

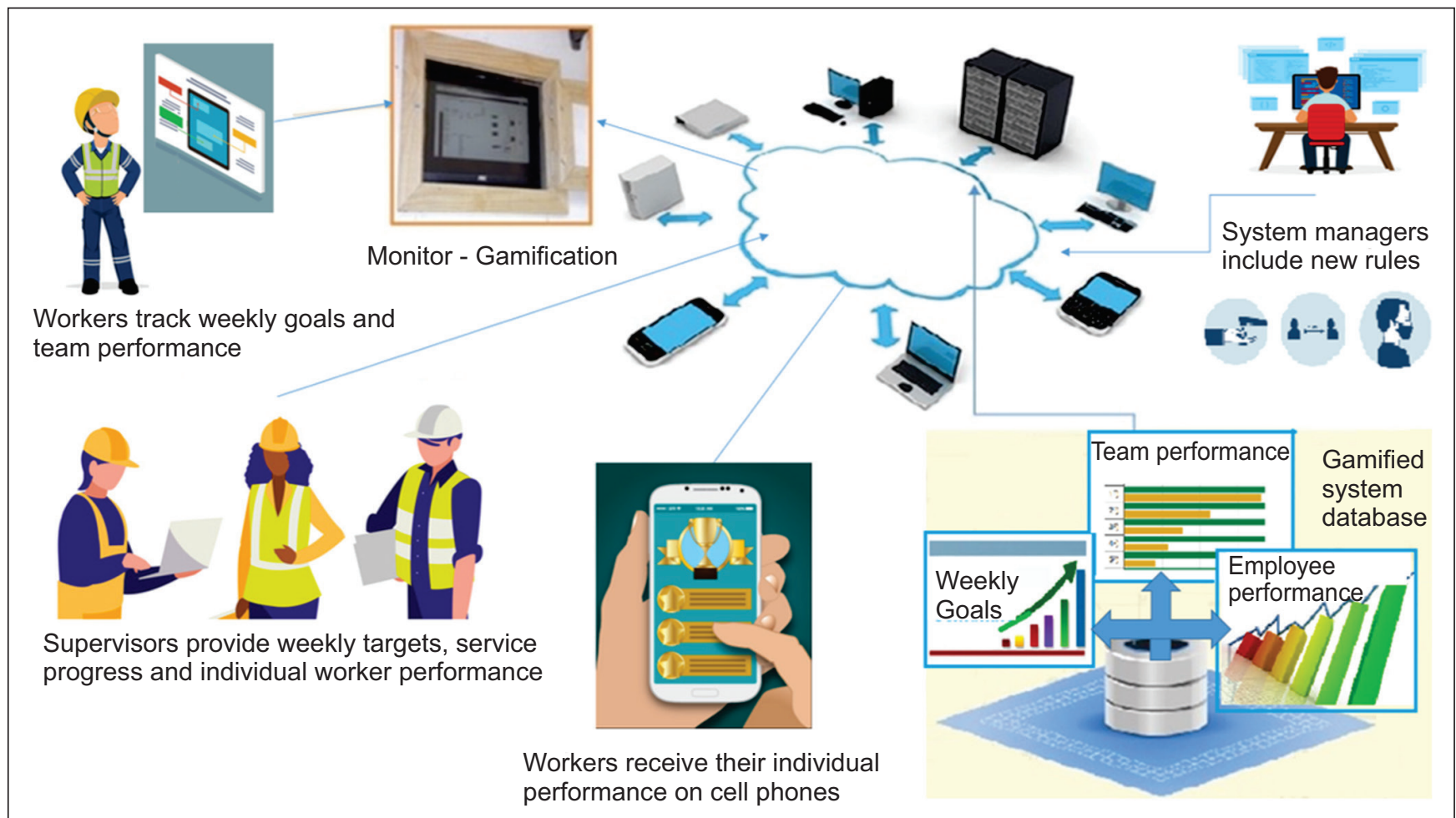

Source: Public domain images (Apadted). 
communication between managers and the workforce. Future work will be the modeling and validation of the system with a group of engineers and construction professionals to design the web version.

\section{References}

1. Souto X. COVID-19. Recital, 2020, 2(1), 12-36.

2. Coronavírus - Cartilha CBIC 2020. Disponível em: https://www.sinduscon-ba.com.br/coronavirus/index. html acesso em: 05 de novembro de 2020.

3. Kostela L.Application of the new production philosophy to construction. Stanford: Stanford University, 1992.

4. EL-Sabek L, McCabe B. Coordination Challenges of Production Planning \& Control in International MegaProjects: A Case Study. Lean Construction Journal, 2017.

5. Brady D, Tzortzopoulos P, Rooke J, Formoso CT, Tezel A. Improving transparency in construction management: a visual planning and control model. ECAM 2018;25(10):1277-1297.

6. Leite R, Costa D, Neto H, Durao F. A.Gamification technique for supporting transparency on construction sites: a case study. ECAM 2016;23(6):801-822

7. Leite R, Costa D, Neto H,Vieira Lima M. Gamificação: uma solução para melhoria da comunicação com os trabalhadores e da transparência da obra. In: Leite, Jessica e Suzart, Renaielma. O Universo da Engenharia Civil. Editora Mente Aberta 2018:150-166.

8. Morêda Neto H, Leite R, Costa D, Durão F. Visual communication panels for production control using gamification techniques. In IGLC-22 2014:689-702.

9. Deterding S, Sicart M, Nacke L, O'Hara K, Dixon D. Gamification. using game-design elements in nongaming contexts. In: CHI'11 2011:2425-2428
10. Huotari K, Hamari J. A definition for gamification: anchoring gamification in the service marketing literature. Electronic Markets 2017;27(1):21-31.

11. Seaborn K, Fels D. Gamification in theory and action: A survey. IJHC studies 2015;74:14-31.

12. Zichermann G, Cunningham C. Gamification by design: Implementing game mechanics in web and mobile apps. O'Reilly Media, Inc., 2011.

13. Werbach K, Hunter D. For the win: How game thinking can revolutionize your business. Wharton Digital Press, 2012.

14. Sailer M, Hense J, Mayr S, Mandl H. How gamification motivates: An experimental study of the effects of specific game design elements on psychological need satisfaction. Computers in Human Behavior 2017;69:371-380.

15. Chou Y. Actionable gamification: Beyond points, badges, and leaderboards. Packt Publishing Ltd, 2019.

16. Schlemmer E. Projetos de aprendizagem gamificados: uma metodologia inventiva para a educação na cultura híbrida e multimodal. Momento-Diálogos em Educação 2018;27(1):42-69.

17. Deterding S. Gamification in management: Between choice architecture and humanistic design. JMI, 2019;28(2):131-136.

18. Korn O, SchmidtA. Gamification of business processes: Re-designing work in production and service industry. Procedia Manufacturing 2015;3:3424-3431.

19. Warmelink H, Koivisto J, Mayer I, Vesa M, Hamari J. Gamification of production and logistics operations: Status quo and future directions. JBR 2020;106:331340.

20. Dresch A, Lacerda D, Júnior J. Design science research: método de pesquisa para avanço da ciência e tecnologia. Bookman Editora, 2015. 